\title{
/s/-Lenition and the Preservation of Plurality in Modern Occitan ${ }^{1}$
}

\author{
Laurel MacKenzie* \\ University of Manchester
}

\begin{abstract}
This paper examines the variable weakening and deletion of /s/ in the Languedocian variety of Modern Occitan, with particular attention to how it has affected the system of plural marking in noun phrases. Using data from linguistic atlases, I demonstrate that /s/-lenition in this variety involves a stage of vocalization to [j]. I find that, where /s/ on the definite article has vocalized to [j], the immediately-preceding vowel of the definite article has undergone concomitant raising to [e]. This raising appears to preserve the difference between singular and plural despite the plural's weakening /s/. I argue that these results support Labov's (1994) hypothesis that the meaning of a weakening element may be transferred to a stable, co-occurrent one.
\end{abstract}

\section{Introduction}

This paper examines the variable weakening and deletion of /s/ in the Languedocian variety of Modern Occitan, with particular attention to how this has affected the system of plural marking in noun phrases. As is common in other Romance languages, the dialect of Occitan under study marks plurality on a noun phrase by affixing an -s plural morpheme to the article, the noun, and any adjectives, as in (1).

(1)

$\begin{array}{lll}\text { [la-s } & \text { 'kãmbo-s } & \text { pe'lydo-s] } \\ \text { DEF.FEM-PL } & \text { leg-PL } & \text { hairy-PL } \\ \text { 'hairy legs' } & & \end{array}$

However, as in Spanish and Portuguese (see, e.g., Guy, 1981; Hernández-Campoy and Trudgill, 2002; Poplack, 1980; Ranson, 1991; Terrell, 1977), the /s/ of the plural can variably undergo weakening and deletion. This paper uses data from dialect atlases (Ravier, 1978, 1982, 1986, 1993) to examine what happens to the singular-plural distinction in Occitan when /s / is lost: is there a tendency to preserve meaning? By what route?

I demonstrate that /s/-lenition in Languedocian involves a stage of vocalization to [j]. When the /s/ plural marking on the definite article vocalizes, the article vowel is raised to [e], preserving the difference between singular and plural despite the plural's weakening /s/. I argue that these results support Labov's (1994) hypothesis that the meaning of a weakening element may be transferred to a stable, co-occurrent one.

This paper is structured as follows. Section 2 provides background information on the language under

\footnotetext{
${ }^{1}$ An earlier version of this paper appeared in Penn Working Papers in Linguistics 16.2.

*Address for correspondence: Laurel MacKenzie, School of Arts, Languages and Cultures, University of Manchester, Oxford Road, Manchester M13 9PL, United Kingdom. + 44 (0)161 2753152.

(Email: laurel.mackenzie@manchester.ac.uk)
}

study, including previous work on /s/-loss in Occitan, and the source of the data. Section 3 examines the weakening of the plural -s marker on nouns and definite articles, followed by an examination of concomitant effects on the vowel of the definite article. I conclude with a discussion of the role of meaning preservation in language change (Section 4).

\section{Background}

\subsection{Language and Data}

Occitan is the generic name used to refer to a collection of varieties, distinct from French, spoken throughout Southern France. Occitan is also known as Langue d'Oc and, historically, Provençal, though today this term refers properly only to a particular Occitan variety, that spoken in Provence. The variety of Occitan examined in this paper is Languedocian.

Ethnologue places both Occitan and French in the Gallo-Iberian branch of Romance languages (Lewis, Simons \& Fennig, 2014); the two followed different paths of development beginning in the 5th century with the invasion of Gaul by foreign tribes. Northern France sustained invasions by Britons, Saxons, and particularly Franks, who lent their name to the nation, while Southwest France, with the exception of Gascony, which was invaded by the Basques, received minimal outside influence. The Latin language and Roman culture thus remained more intact in Southern than Northern France, given the different levels of occupation in each half of the country. By the 12th century, the vernaculars of Northern and Southern France were considered different languages, known as the Langue d'Oil in the North and the Langue d'Oc in the South, after each language's affirmative particle (Pope, 1952). 

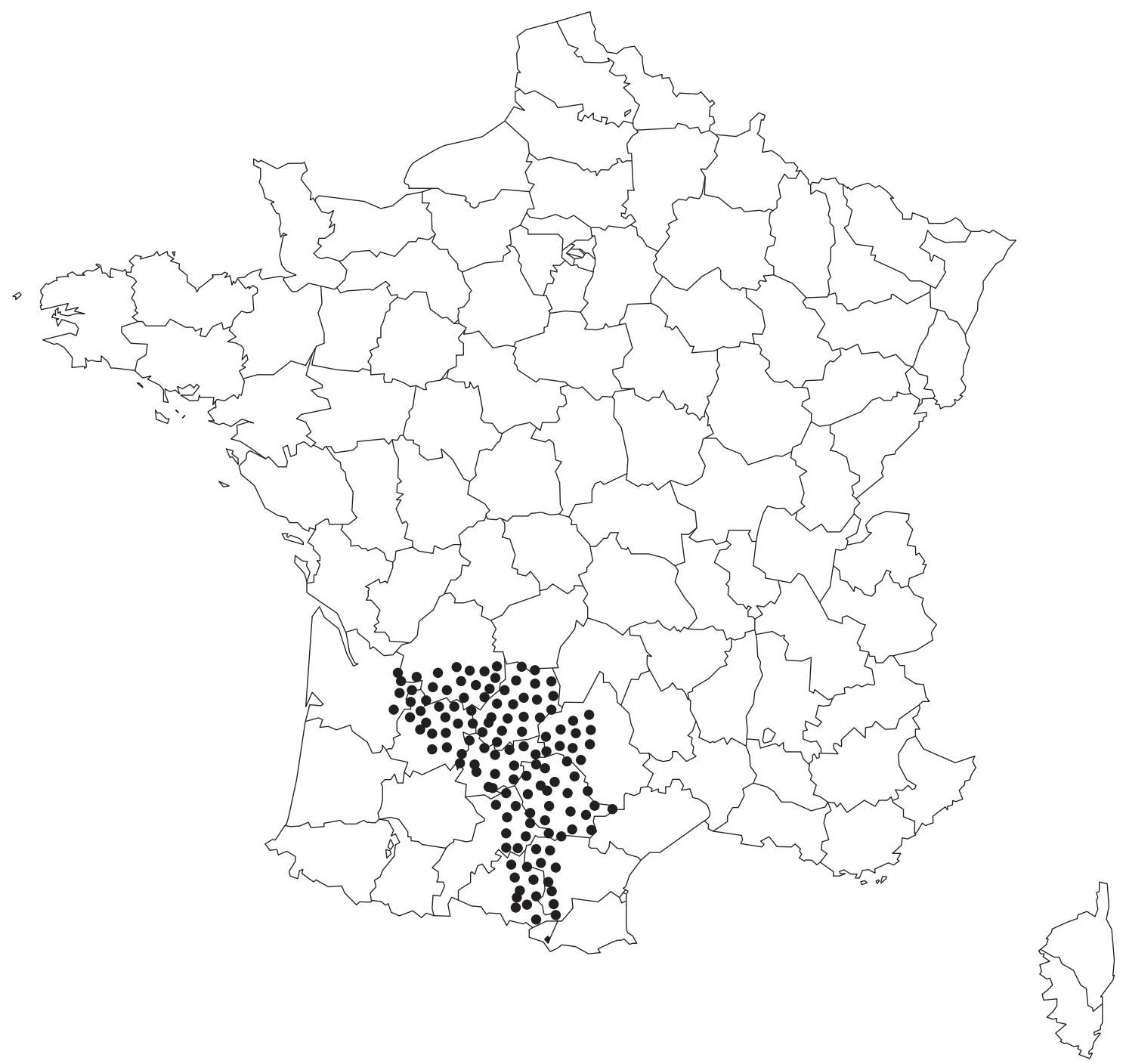

Map 1. The 131 localities sampled in ALLOc.

Anglade ([1921] 1977) placed the number of speakers of Occitan at 12 or 14 million; the 1999 French census found fewer than two million people who said that their parents had spoken to them at least occasionally in Occitan in their childhood, and only 250,000 who had spoken it to their own children (Héran, Filhon, and Deprez, 2002). Ethnologue places the number of speakers in France at only 110,000 (Lewis et al., 2014). As a reviewer observes, the difficulties inherent in polling speakers on their use of minority languagesparticularly in France, where minority languages have been aggressively marginalized for centuries (Schiffman, 1996) - mean that we should interpret these numbers with some caution, in case some speakers of Occitan were reluctant to reveal themselves to censustakers. Still, sources agree in recognizing the language as endangered (Lewis et al., 2014; Moseley, 2010).

The data used in this paper come from the Atlas linguistique et ethnographique du Languedoc occidental (abbreviated henceforth as ALLOc; Ravier, 1978, 1982, 1986, 1993). The area sampled in ALLOc is bordered by the Dordogne river to the north and the Garonne river to the west; the eastern boundary of the sample was determined based on the sample sites used in other linguistic atlases (the Atlas linguistique et ethnographique du Massif Central, the Atlas linguistique du Languedoc oriental) as well as topographical, cultural, and ethnographic considerations (for instance, to avoid dividing what was felt by natives to be a coherent region). The sampled area encompasses, in whole or in part, the present-day departments of Ariège, Aude, Haute-Garonne, Tarn, Tarn-et-Garonne, Lot-et-Garonne, Aveyron, Lot, Gironde, Dordogne, and (with one point represented only) Corrèze. It includes the major city of Toulouse but not that of Bordeaux. Data were gathered between 1967 and 1972, collected from 131 localities 15-17 km (approx. 9-11 mi) apart, as plotted in Map 1. (Subsequent plots will zoom in on the region under study.) 
Approximately 1200 lexical items were elicited for the atlas, with each lexical item elicited once per locality. $73 \%$ of the 265 primary informants were aged 60 or older, and $72 \%$ were male. Many worked in agricultural professions. This is, of course, reminiscent of the 'nonmobile, older, rural males' (NORMs) sought out as informants in many dialectological studies (Chambers \& Trudgill, 1998:29), though the atlas gives no indication of whether this was a deliberate choice on the part of the researchers or an inevitability due to a difficulty in finding Occitan speakers in more urban areas. Indeed, a respondent from the city of Toulouse was included in the sample, as were women and young people (though these non-NORM informants are often identified as having been family members of the older males).

To elicit forms, researchers provided a French word and asked the informant for the Occitan translation, so all informants had some level of bilingualism. Data were collected by semantic category and were phonetically transcribed.

\subsection{Linguistic Background}

We can see a historical parallel to the /s/-lenition of Languedocian Occitan in a similar process that occurred in the evolution of French. Old French had two cases, a nominative and an oblique; the oblique case, which marked plural by affixing /s/ to articles and nouns, was the source of the Modern French single-case system. Preconsonantal /s/ was lost by the 12th or 13 th century, and / s / before pause by the 17th century, which led to the system French has today, in which an orthographic $\langle\mathrm{s}\rangle$ is attached to plural nouns and articles but is not pronounced in the vast majority of contexts. Instead, plurality in Modern French is conveyed by another mechanism: change in the vowel of the definite article from singular / la/ (feminine) or /lə/ (masculine) to plural /le/ (both genders). The only place where /s/ still manifests itself is in the process of liaison before a vowel: for instance, the vowel-initial noun l'heure [lœu] 'the hour' has as its plural les heures [lez œв]. In the absence of liaison, though, plural meaning for nouns that form their orthographic plural in $\langle\mathrm{s}\rangle$ is expressed only by the vowel of the definite article.

The chain of events that gave rise to this pluralconveying vowel alternation is not known. Seklaoui (1989:8) refers to the /e/ in the plural definite article as the result of "an obscure phonetic evolution." Spence (1976) proposes that its source is as follows: The vowels of the Vulgar Latin plural definite articles los and las were reduced to [ə], which was then variably lengthened compensatorily after loss of the following /s/, and this [ə] then raised to [e]. He admits, though, that there is no clear phonetic mechanism by which this could have occurred, and that the need to disambiguate singular from plural must have been an influencing factor. In this paper, I propose that the patterns found in the related language of Occitan may elucidate the question.

This is not the first study of /s/-deletion and its effects on plurality in Modern Occitan. Eckert (1969, 1985) performed a similar study using data gathered from the Atlas Linguistique de la France (henceforth ALF), for which fieldwork was carried out between 1897 and 1901. She found evidence for two sound changes in Southern France: One deleting the plural /s / marker, which was restricted only to the northern half of the region she examined, and a concomitant change of *a $>$ [o], which was more widespread, but which showed grammatical conditioning. Specifically, in the northern half of the region under study, where plural /s/ had been deleted, the * $\mathrm{a}>[\mathrm{o}]$ change had gone to completion in singulars only; in the area where /s / was retained, the *a $>$ [o] change had gone to completion in both singulars and plurals (as sketched in (2)). Directly between the /s/-deleting North and the /s/-retaining South, Eckert identified an area of "number disturbance," in which /s/ was variably retained; this region was bisected by the isogloss delimiting the change of *a to [o] in plurals. The upshot of all this is that where the singular-plural distinction was in danger of being lost due to /s/-deletion, the contrast was maintained by the simultaneous *a $>[0]$ change.

Region of /s/-deletion: Region of /s/-retention:

$\begin{array}{cc}\text { (2) *a }>[\mathrm{o}] \text { in singulars only } & * \mathrm{a}>[\mathrm{o}] \text { in both plurals } \\ \text { sg. lo bello pullo pl. la } & \text { and singulars sg. lo } \\ \text { bella pulla 'the beautiful } & \text { bello pullo pl. los bellos } \\ \text { hen(s)' } & \begin{array}{l}\text { pullos 'the beautiful } \\ \text { hen(s)' }\end{array}\end{array}$

The data provided in $A L L O c$ were collected 70 years after Eckert's ALF data, and reveal that /s/-deletion has continued to spread, even into the area where the *a $>$ [o] change went to completion in both singulars and plurals. Floricic (2010), Barra-Jover (2012), and Sauzet (2012) all use the data in ALLOc (or as-yet unpublished data collected as part of the ALLOc survey) to investigate the status of plural marking in Languedocian in the absence of this "recourse" of final vowel quality. All three authors identify a range of phonological realizations of plurality, which I corroborate below. The present paper additionally expands on these works by providing a comprehensive geographical account of the situation in Languedocian, examining the realization of plural marking on multiple lexical items across the entire region sampled in the atlas. Doing so 


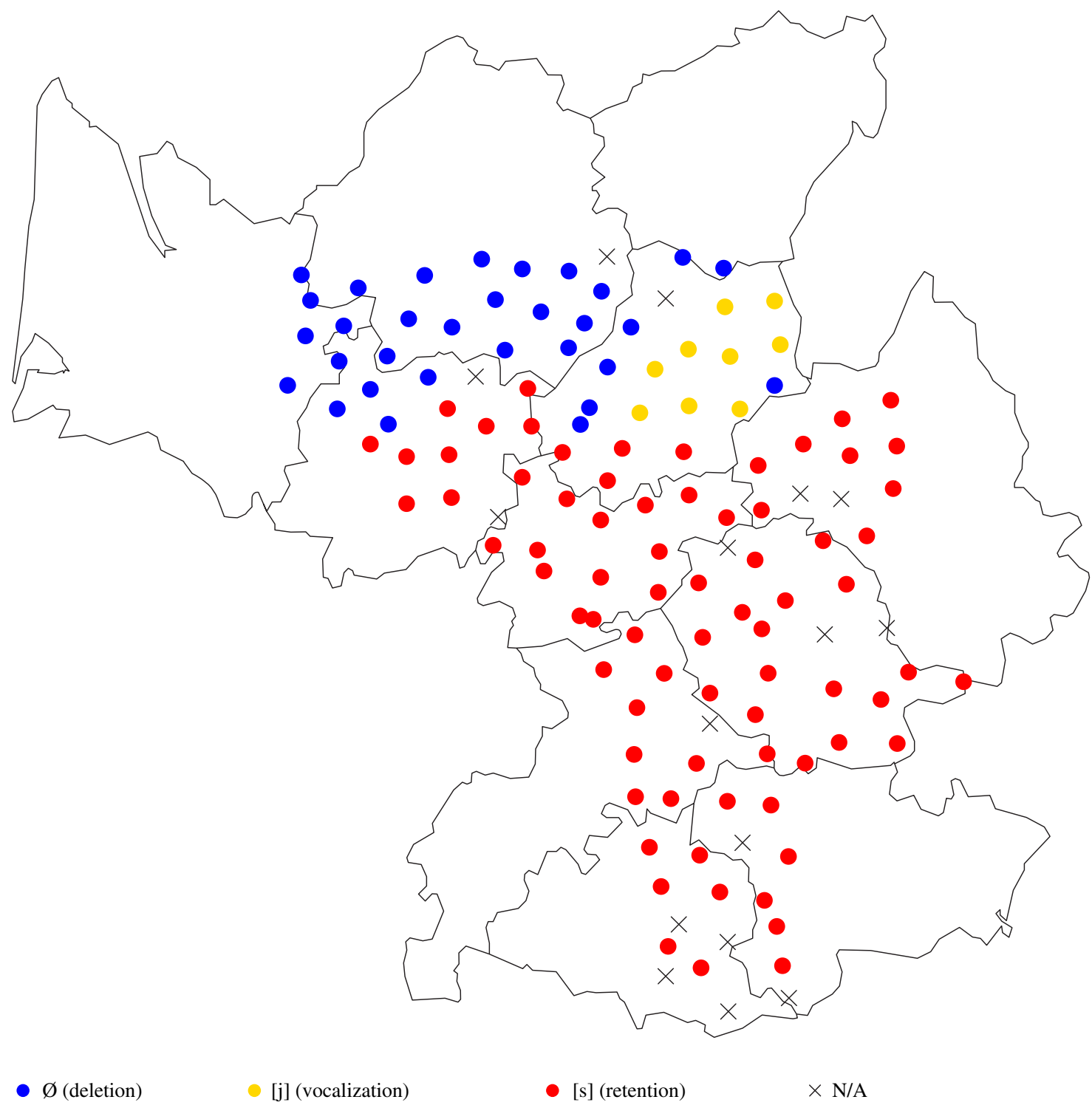

Map 2. Realization of /s/ on the noun of les traces 'animal tracks'.

allows us not only to examine the synchronic state of affairs, but, in comparing neighboring varieties, to hypothesize as to its diachronic development.

\section{Data}

The findings presented in this section are drawn from the realization of plural on the definite article and the noun of eight lexical items. ${ }^{1}$ These eight items were selected based on two criteria: For the majority of localities surveyed, they (a) are of feminine gender and (b) contain a noun beginning with a voiceless stop. These restrictions were made to control for processes independent of /s/-lenition which are known to affect the phonological realization of the definite article. For instance, as in other Romance languages, Languedocian
Occitan marks noun gender in the vowel of the definite article, so nouns were restricted to a single gender (here, the feminine) in order to ensure that all would have the same definite article. Additionally, because the initial segment of a Languedocian noun has been shown to induce allophonic variation in the final segment of the definite article that precedes it (Barra-Jover, 2012; Ronjat, 1932; Sauzet, 2012), the manner and voicing of the initial consonant were restricted as a control (here, to voiceless stops only).

Any data point in which the noun was not feminine, not voiceless stop-initial, or not plural (due to, for instance, a location having a collective singular term for an item) was omitted from this study, and is represented in the maps below as an 'N/A' point. When an $A L L O c$ informant provided two possible realizations for 


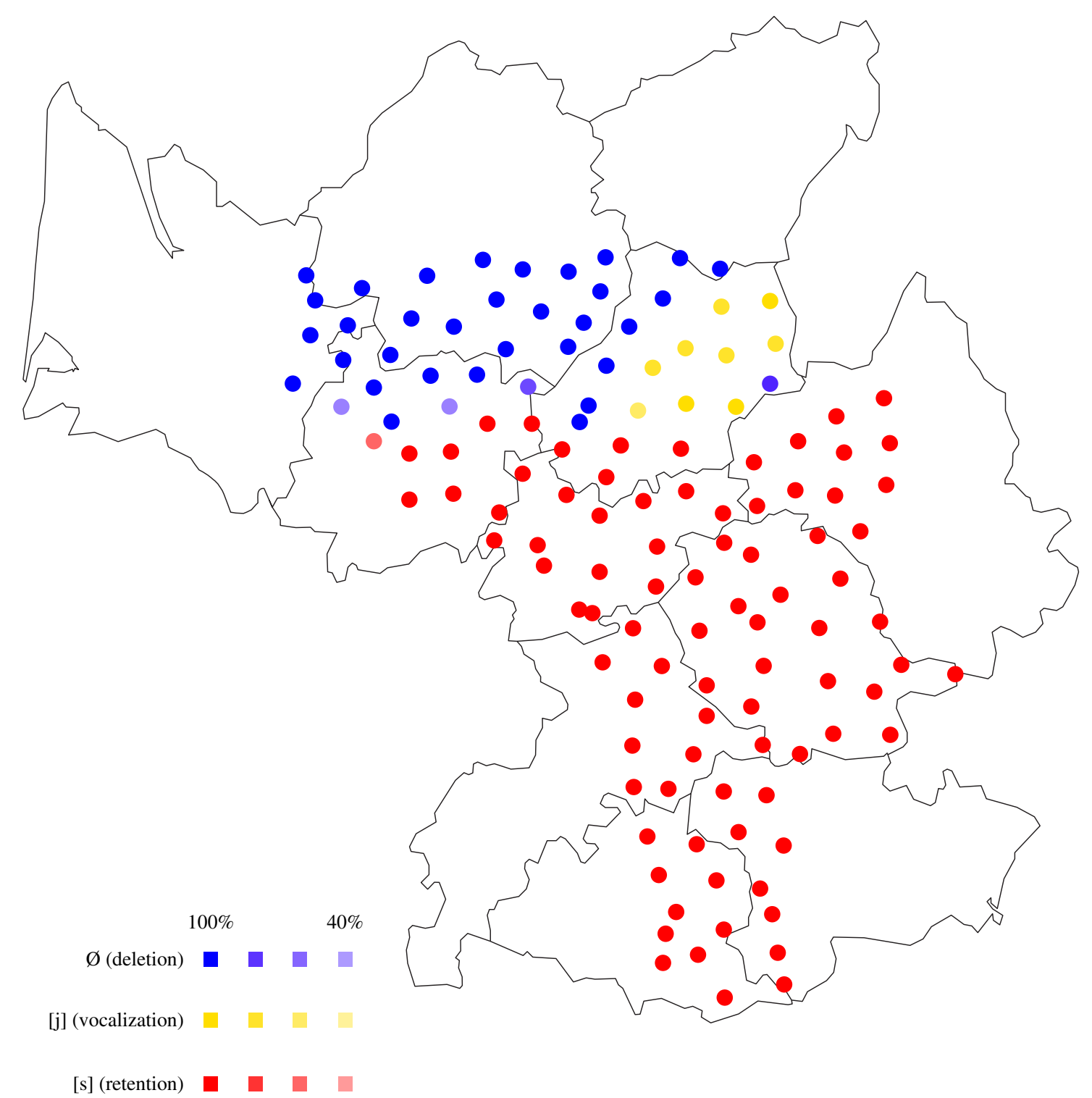

Map 3. Percent realization of most common variant of /s/ on the noun across eight lexical items. More saturated colors indicate a higher representation of that variant across the eight items.

a locality, the first of these was selected for analysis, based on the remark in $A L L O c^{\prime}$ 's front material that "in a very general fashion, the order of forms on the map is the order in which they were provided by the informant" (Ravier, 1978:xiv, translation mine).

Findings below will frequently be exemplified with a single lexical item, but reference will be made to that item's typicality vis-à-vis the other seven items examined.

\subsection{Realization of /s/ on the Noun}

Map 2 plots the realization of /s/ on the noun only, with one point for each location surveyed in $A L L O c$, for the lexical item les traces 'animal tracks' (ALLOc's map 352). Points represented with a blue dot show no marker of plurality on the noun, e.g. ['pjado] (point 24.30), which I term 'deletion.' Points represented with a yellow dot are those in which /s/ on the noun surfaces as [j], e.g. [pe'nadj]] (point 46.17), which I term 'vocalization.' ${ }^{2}$ Points represented with a red dot are those in which /s/ on the noun surfaces as [s] (or, less frequently, some other fricative with a buccal articulation,

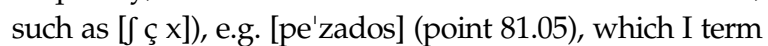
'retention.' ${ }^{3}$ Points represented with a black ' $x$ ' were discarded as not applicable for the reasons elucidated above (i.e., the informant's response was not feminine, not plural, or did not contain a voiceless stop-initial noun), or because the informant was unable to provide a response. ${ }^{4}$

Map 2 reveals that vocalization of /s/ to [j], while not particularly prevalent in the area under study, 


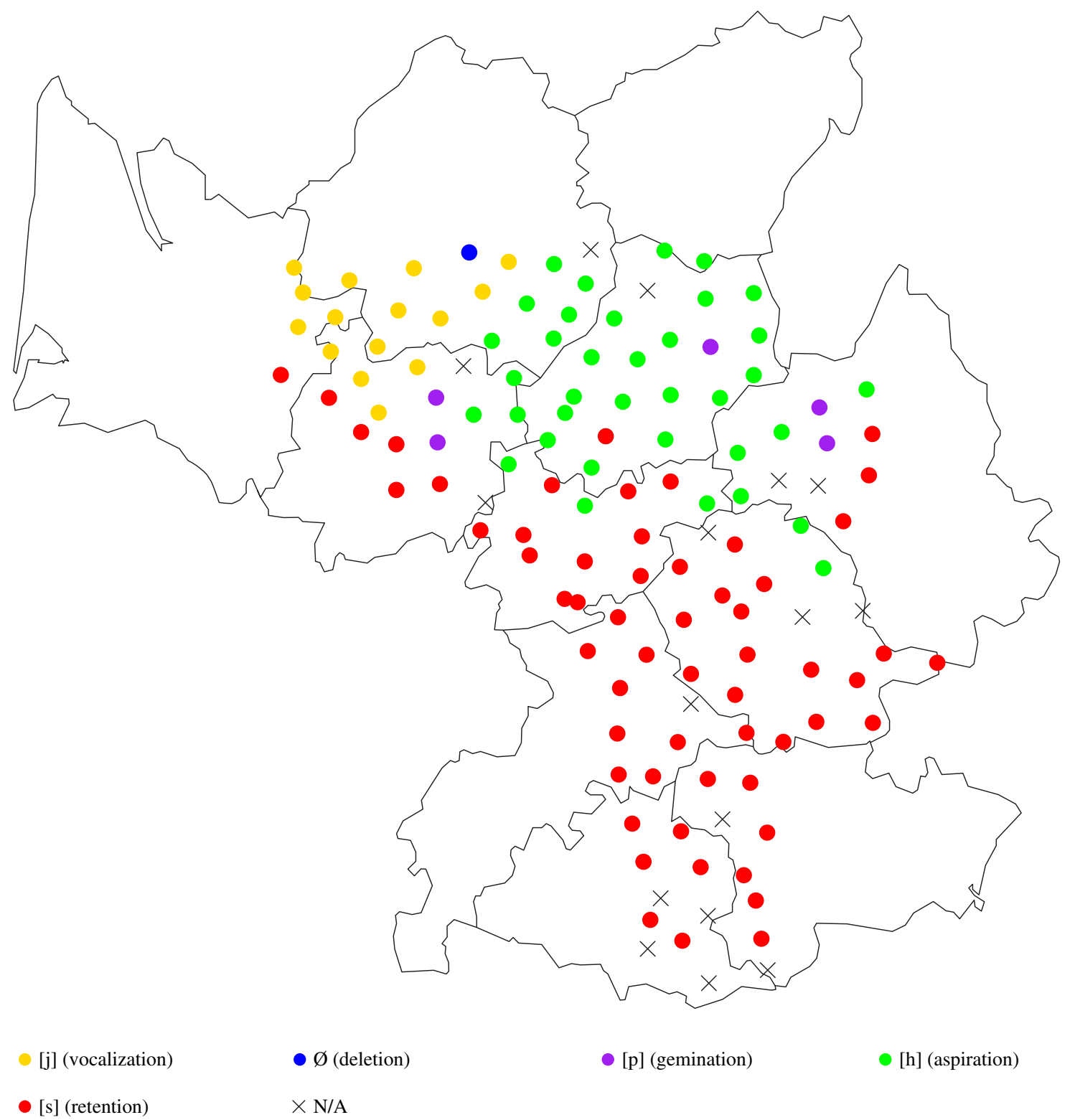

Map 4. Realization of /s/ on the article of les traces.

is well-represented in a tight cluster of localities in the northeast sector. Vocalization is not attested as a stage of /s/-loss in Ferguson's (1990) typology of [s] > [h] changes, and likewise is not mentioned as a variant in those synchronic studies of /s/-weakening in Spanish and Portuguese cited earlier. In Occitan, it is frequently identified as an allophonic variant of / s / which appears before voiced consonants (Barra-Jover, 2012; Ronjat, 1932; Wheeler, 1988), but the fact that the data points in Map 2 have been restricted to only those in which the article precedes a voiceless stop-initial noun means that [j] must be a stage on the /s/-weakening trajectory. Indeed, Seklaoui (1989) does list vocalization as a possible, though rare, outcome of /s/-weakening, citing examples from Italian as well as Occitan.
To show that the patterns of /s/-realization depicted in Map 2 are not specific to the lexical item les traces, I calculated the percentage of each variant of /s/ for each locality across all eight lexical items examined. The most common variant for each locality is plotted in Map 3, with a color saturation indicating how common that variant was across the eight lexical items (the darker the color, the more well-represented the variant). For instance, a locality for which [s] was retained on the noun in all eight lexical items examined will be plotted as a dark red dot; a locality which had retention of [s] for one item, vocalization to [j] for four items, and deletion of /s/ for three items will be plotted as a light yellow dot (indicating that [j] was the most common variant across the eight items, but that it was only 


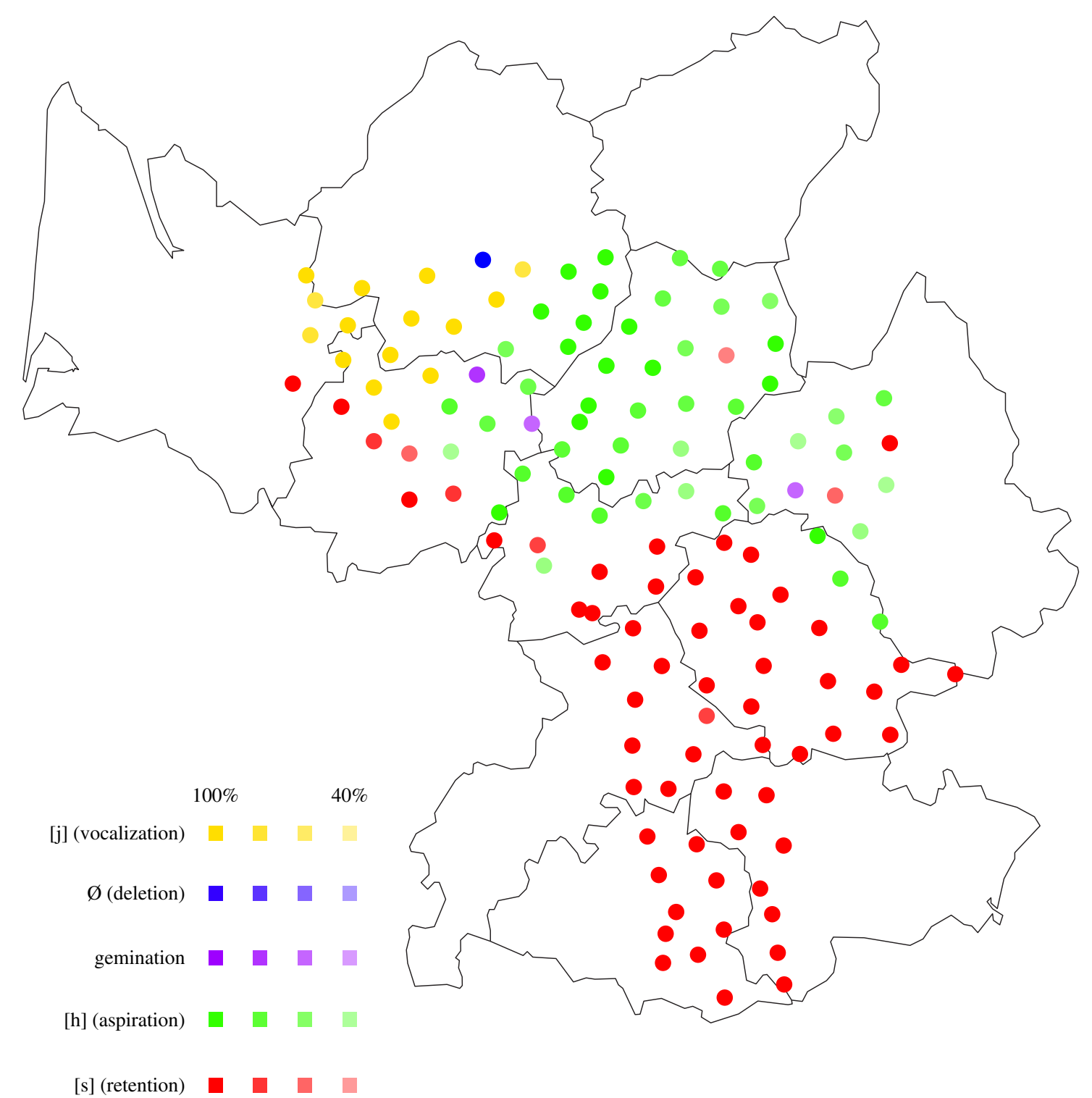

Map 5. Percent realization of most common variant of /s/ on the article across eight lexical items. More saturated colors indicate a higher representation of that variant across the eight items.

represented in $50 \%$ of the observed forms)..$^{5}$ As in Map 2, buccal fricatives other than [s] (e.g. [ ç x]) have been plotted as instances of retention. Map 3 indicates that, for all but a few border towns, the pattern demonstrated by les traces holds for the other lexical items examined.

Map 3 allows us to identify the northwest sector of the region under study as being the most advanced in /s/-weakening (having no overt plural marking on its nouns), the central/southern portion as being the most conservative (having not yet begun to weaken /s/ in any way), and the northeast sector as being somewhere in between (having lenited its realization of / $/$ to [j] but not gone so far as to delete it). These three realizations could be viewed as points on a single trajectory (with /s/ first weakening to [j] and then deleting entirely); alternatively, there could be two different trajectories of /s/-lenition, one in which /s/ deletes with no intermediate stage of [j], and another in which /s/ vocalizes (potentially to delete later on). The present data don't obviously argue for one or the other, and the existence of a unified trajectory of /s/-lenition is not crucial to the present study, so I remain agnostic on this point.

\subsection{Realization of /s/ on the Article}

Map 4 shows the realization of /s/ on the article of les traces. In addition to retained (e.g. [las pe'zados], point 81.05), vocalized (e.g. [lej 'pjado], point 47.02), and deleted $^{6}$ (e.g. [la: pjo'da], point 24.10) variants—plotted as in the previous maps-aspiration of /s/ to [h] 


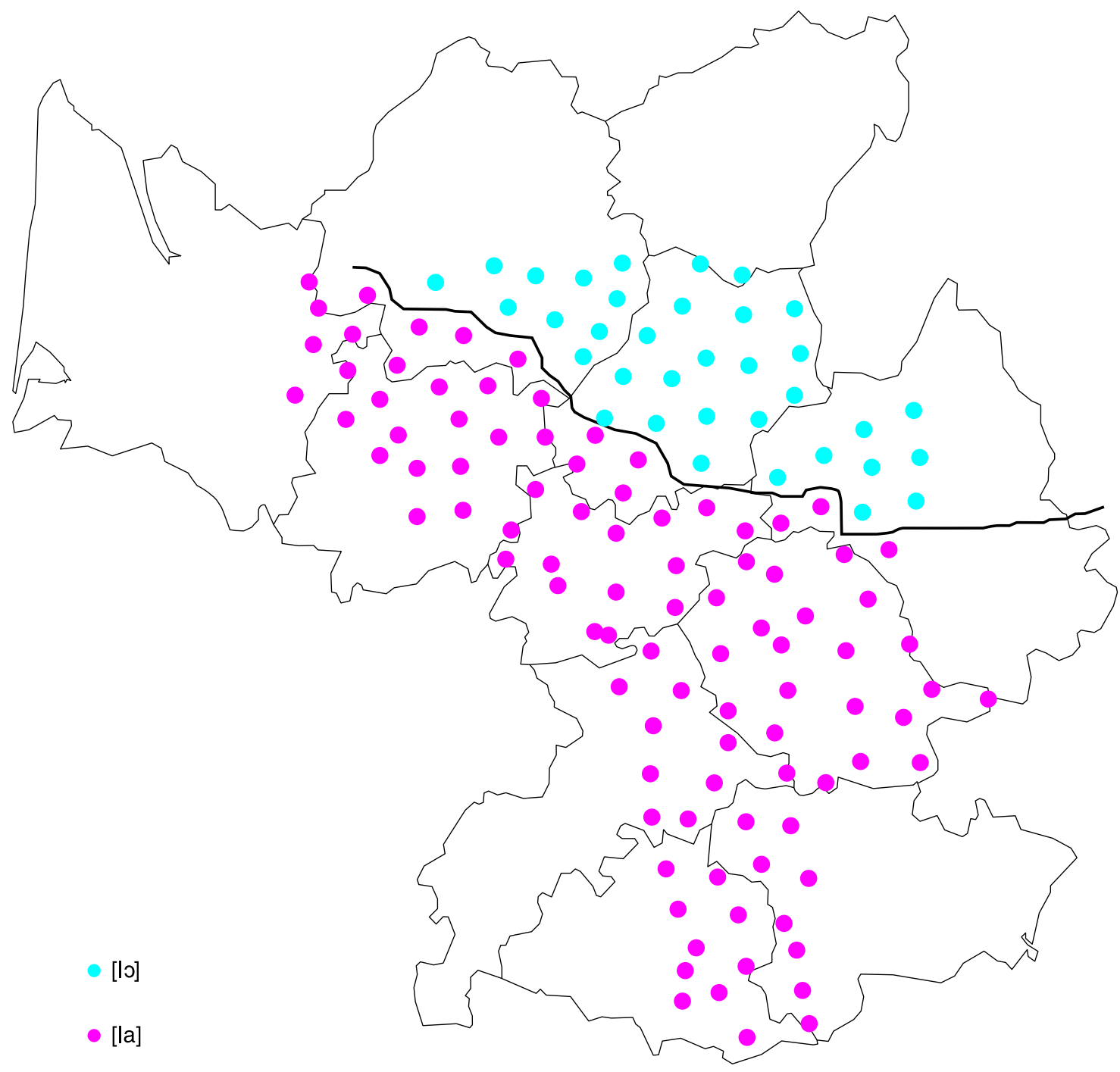

Map 6. Vowel quality of the singular definite article.

(e.g. [lah 'pjados], point 82.12), plotted in green, is observed; /s / may also fully assimilate to the following consonant (e.g. [lap 'pjado], point 47.10), resulting in a geminate (plotted in purple).

Map 4 shows that the southern half of the region under study again behaves conservatively, with [s] retained on the article as it was on the noun. Also, more generally, /s / on the article has not advanced as far in the weakening process as had /s/ on the noun, with only one point showing total deletion of /s/. More advanced weakening on nouns than articles has been similarly found in studies of synchronic /s/-lenition in Spanish and Portuguese (Cedergren, 1973; Guy, 1981; Poplack, 1980).

Map 5 shows the same type of plot as Map 3, with the most attested variant across the eight lexical items plotted in a color saturation indicative of how common it is. There is somewhat more inter-item inconsistency in the realization of article /s/ than there was for noun /s/, as indicated by the greater number of lightercolored points in Map 5 than in Map 3; indeed, the mean proportion of use of the most common variant is 0.977 for noun /s / and 0.891 for article /s/. Still, the pattern evident in les traces is largely shared by the other lexical items under examination.

Again, the northeast, northwest, and southern regions show differing realizations, but again, there is no obvious indication of whether they represent successive stages on a continuum of $[\mathrm{s}]>[\mathrm{h}]>[\mathrm{j}]$, or distinct paths of lenition $([\mathrm{s}]>[\mathrm{h}] ;[\mathrm{s}]>[\mathrm{j}])$.

\subsection{Article Vowel Quality}

The final factor to examine is the quality of the vowel in the definite article. As outlined in Section 2.2, definite article vowel quality plays a crucial role in disambiguating singular from plural nouns in the related language of French. 


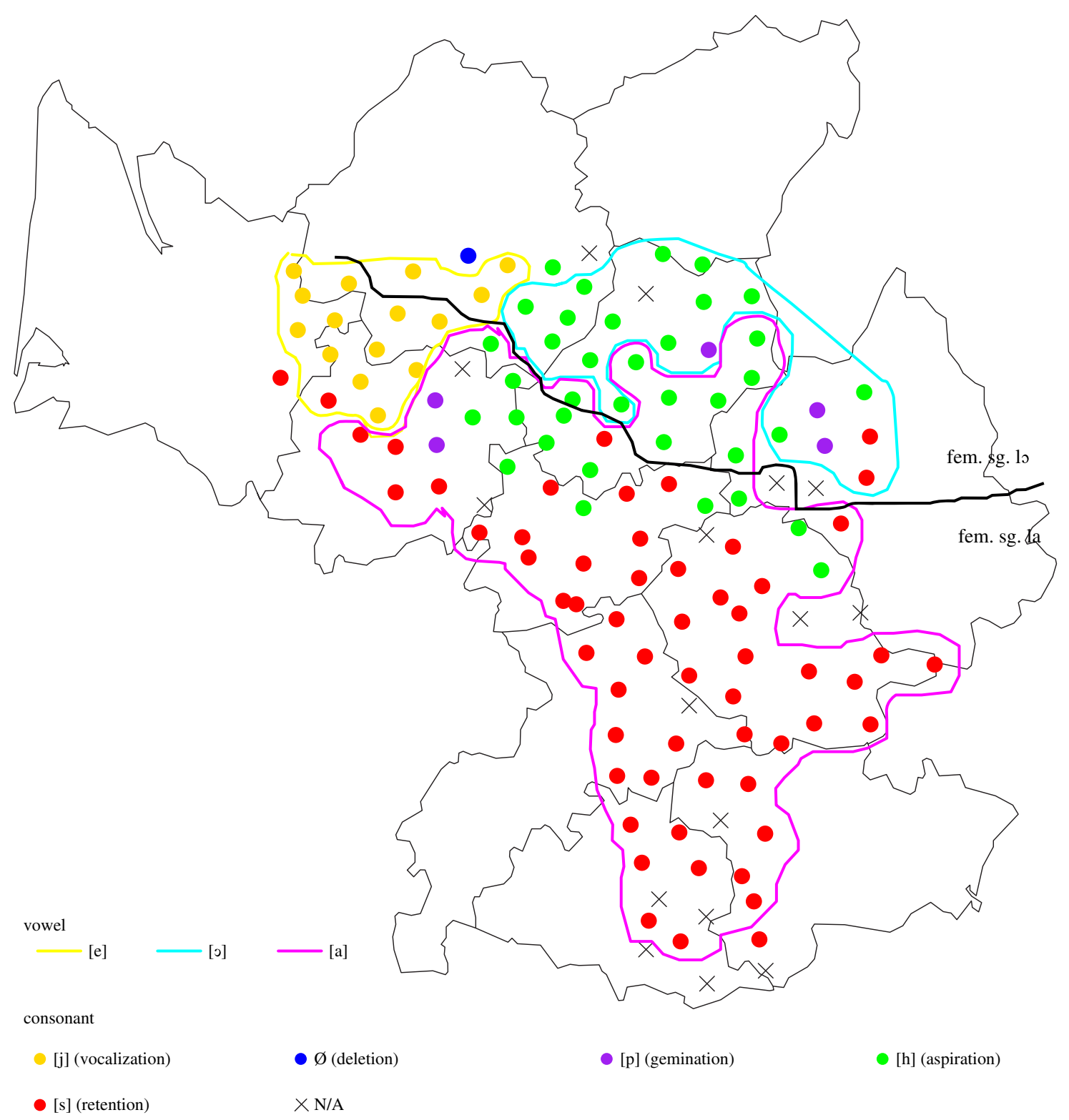

Map 7. Vowel quality of the plural definite article (isoglosses) and realization of /s/ on the article of les traces (points). Black isogloss marks [lo]/[la] split in the singular definite article.

Map 6 shows the vowel quality of the singular definite article in the region under study (based on ALLOc's map 1), revealing that the region can be bisected into a [b] region in the northeast and a [la] region in the southwest. The default assumption is that this vowel quality will be maintained in the plural, as it is in traditional dialects of Occitan (Wheeler, 1988) and in other Romance languages.

Map 7 superimposes isoglosses indicating the observed vowel quality of the plural definite article on the plot from Map 4 depicting the realization of /s/ on the article of les traces. The black isogloss reproduces the $[\mathrm{l}] /[\mathrm{la}]$ split in the singular definite article from Map 6. Map 7 reveals that this same split is maintained throughout much of the region in the plural article as well, with the crucial exception of the northwest sector, where the vowel of the article is, exceptionally, [e]. This region of article [e] coincides almost perfectly with the region in which /s/ on the article has vocalized to [j]. The observed vowel raising is thus almost certainly due to coarticulation of the vowel [a] and the following palatal glide.

Further data reveal, however, that vowel raising in Languedocian plural articles is not purely a mechanical process. Maps 9 and 10 present data for the lexical item les fleurs $d u$ vin 'yeasts that develop on the surface of wine' (map 754 in $A L L O c$ ). Map 8 shows that the manifestation of / $\mathrm{s} /$ on the noun is nearly identical to what it was for les traces in Map 2. 


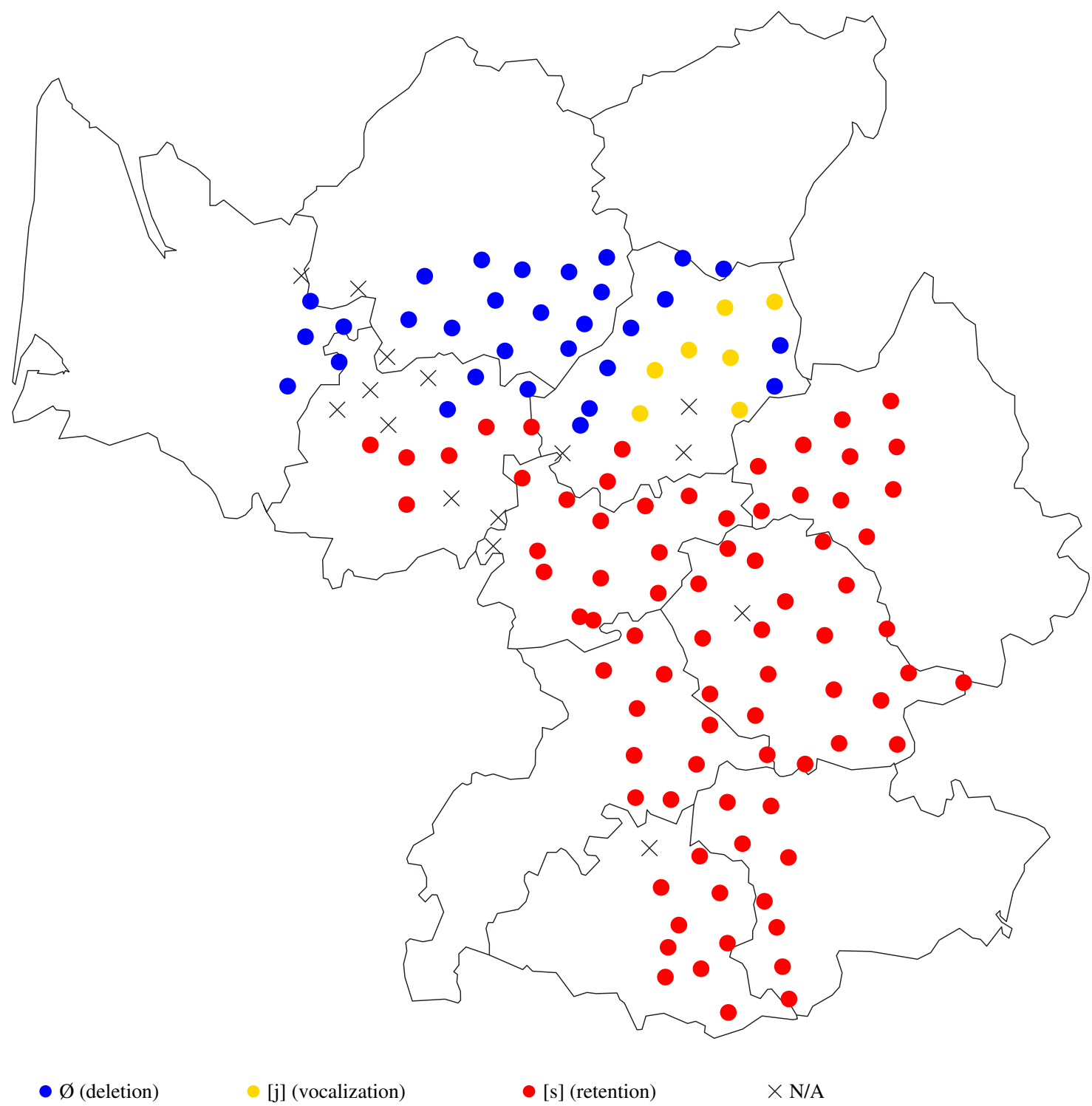

Map 8. Realization of /s/ on the noun of les fleurs du vin 'yeasts that develop on the surface of wine'.

By contrast, Map 9 reveals that the realization of /s/ on the article of les fleurs $d u$ vin differs in a crucial way from that of article /s/ for les traces (Map 4): Much of the southern sector of the region, which retained $[\mathrm{s}]$ in the article of les traces, vocalizes /s/ in the article of les fleurs du vin.

This southern strip of vocalization has a phonological source: It corresponds almost perfectly with the region in which the noun for this lexical item begins with [f] rather than $[\mathrm{k}]$ (as it does elsewhere in the region). This is thus an instance of the allophonic /s/-vocalization mentioned earlier which has heretofore been omitted from analysis. The area in which the noun is fricativeinitial is surrounded by the green isogloss in Map 10; it corresponds well to the southern area which vocalizes /s/ on the article to [j].
But unlike the vocalization depicted in Map 7, this allophonic vocalization does not trigger vowel raising. Map 11 shows a clear difference between /s/-vocalization in the northwest sector and /s/-vocalization in the south: In the south, vocalization has no accompanying vowel change from [a] to [e].

\section{Analysis}

I propose that these findings are interpretable via Labov's (1994) observations on the maintenance of meaning in systems in which a grammatical marker is being lost. Specifically, Labov proposes the following:

When an element of the system is found to co-occur frequently with the signal being deleted, it is increasingly eligible to assume the distinctive 


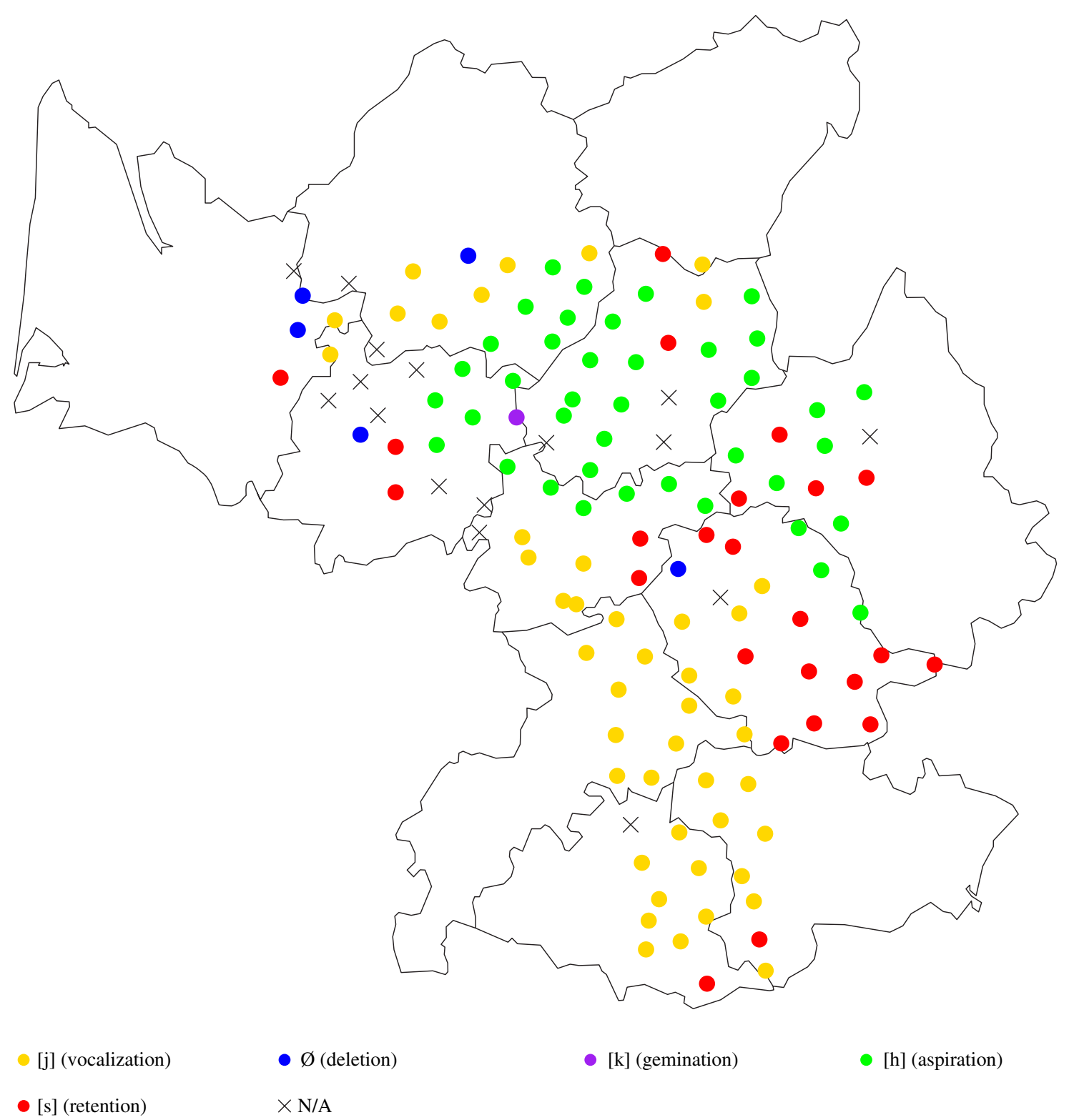

Map 9. Realization of /s/ on the article of les fleurs du vin.

feature representing the semantic feature in question (Labov, 1994:596).

Labov cites as an example of this the loss of the negative marker ne in French, which has been all but replaced with the particle pas. He proposes that this situation has its source in the following development. Given that ne was involved in a process of weakening and deletion and pas was not strictly required for a negative sentence, in the history of French, sentences would inevitably surface which were intended by a speaker as negative but which bore no overt negative marker. These sentences were ambiguous between negative and positive (Labov's "unsupported zeroes," 1994:589), and some learners may have misinterpreted them as positive. Over time, as learners attempted to match their percentage of ne use to that of the negative sentences they received in their input, the unambiguously-negative input they received became more and more skewed toward tokens containing pas, since those that didn't contain pas were prone to be factored out as positives. This eventually resulted in pas taking over as the negative marker, as the loss of ne eventually went to completion.

If an analogous process occurred in Languedocian, we could explain the differing article vowel qualities between the northwest sector and the south in cases like les fleurs $d u$ vin, where both regions vocalize /s / on the article but only the northwest shows concomitant vowel raising. In the south, /s / is consistently retained on the 


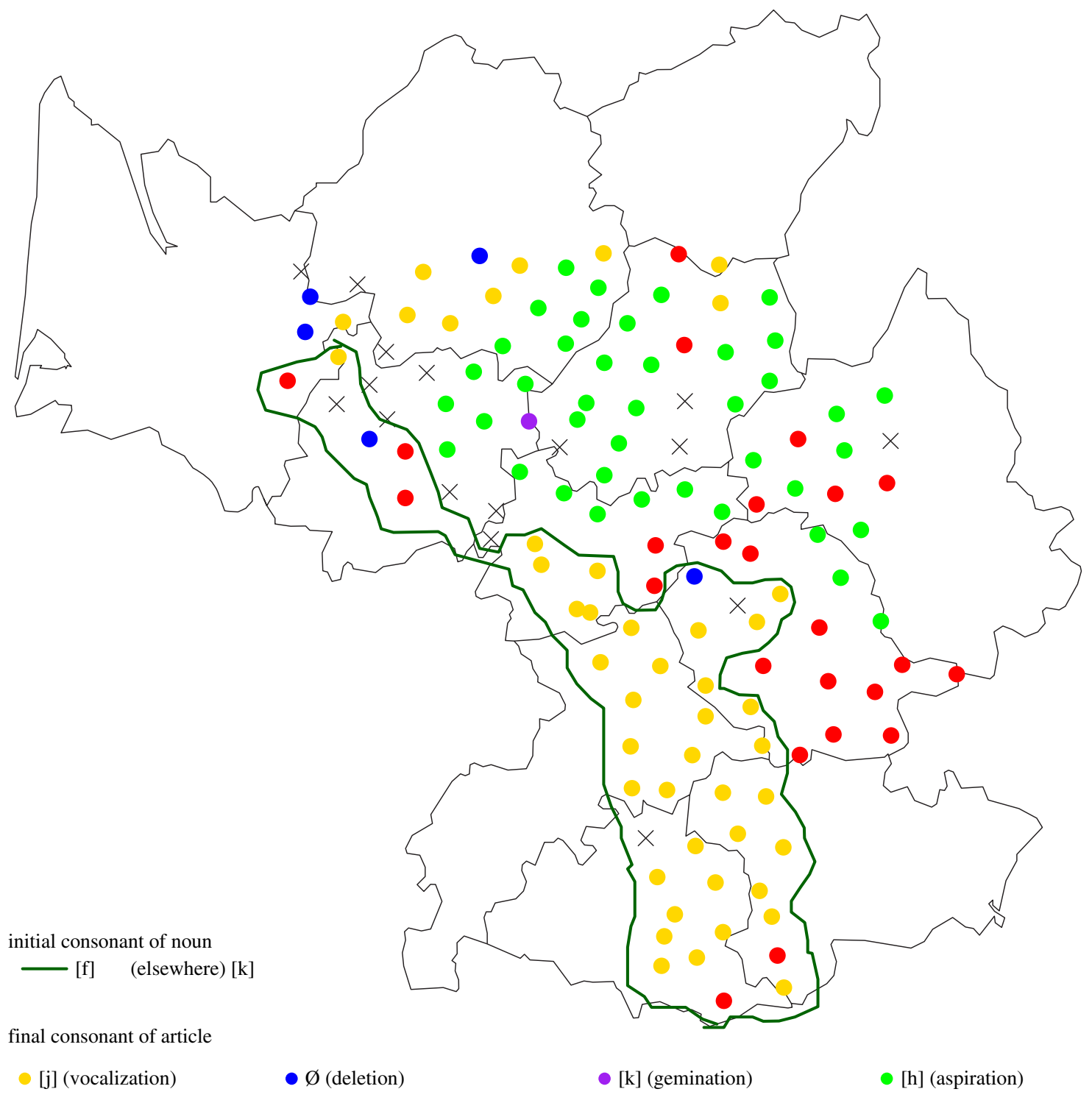

- $[\mathrm{s}]$ (retention) $\times$ N/A

Map 10. Realization of /s/ on the article of les fleurs $d u$ vin. The area encircled in green has a fricative-initial noun (elsewhere, the noun is stop-initial).

noun (Map 8), meaning that there is no possibility of a plural form being mistaken for a singular, even when the /s/ of its article has weakened to [j]. In the northwest, by contrast, the loss of / s / on the noun means that the singular comes to bear a close resemblance to the plural: Only the [j] on the article separates them. If this [j] were itself to be variably deleted, singular-plural ambiguity would result and those tokens in which the vowel had not raised to [e] could be misclassified as singulars. At the same time, a variably retained [j] would trigger vowel raising, meaning that the number of forms unambiguously identified as plurals could eventually shift to those that bore [e] in their article, despite having no consonantal plural marking. In the south, where there are no ambiguous forms, learners would not have any more evidence of plurality from forms in which the vowel was raised than from forms in which it wasn't. As a result, any coarticulation-induced raising would fail to be cemented as part of the linguistic system, instead remaining merely a phonetic variant of the unraised vowel. ${ }^{7}$

This analysis crucially depends on there being ambiguous forms in the northwest to be misrepresented as singular. I have assumed here that such forms arise when [j] is variably deleted, but there is no evidence from $A L L O c$ of such [j]-deletion actually occurring. This is the downside of working with linguistic atlases: we have no access to the synchronic variation present 


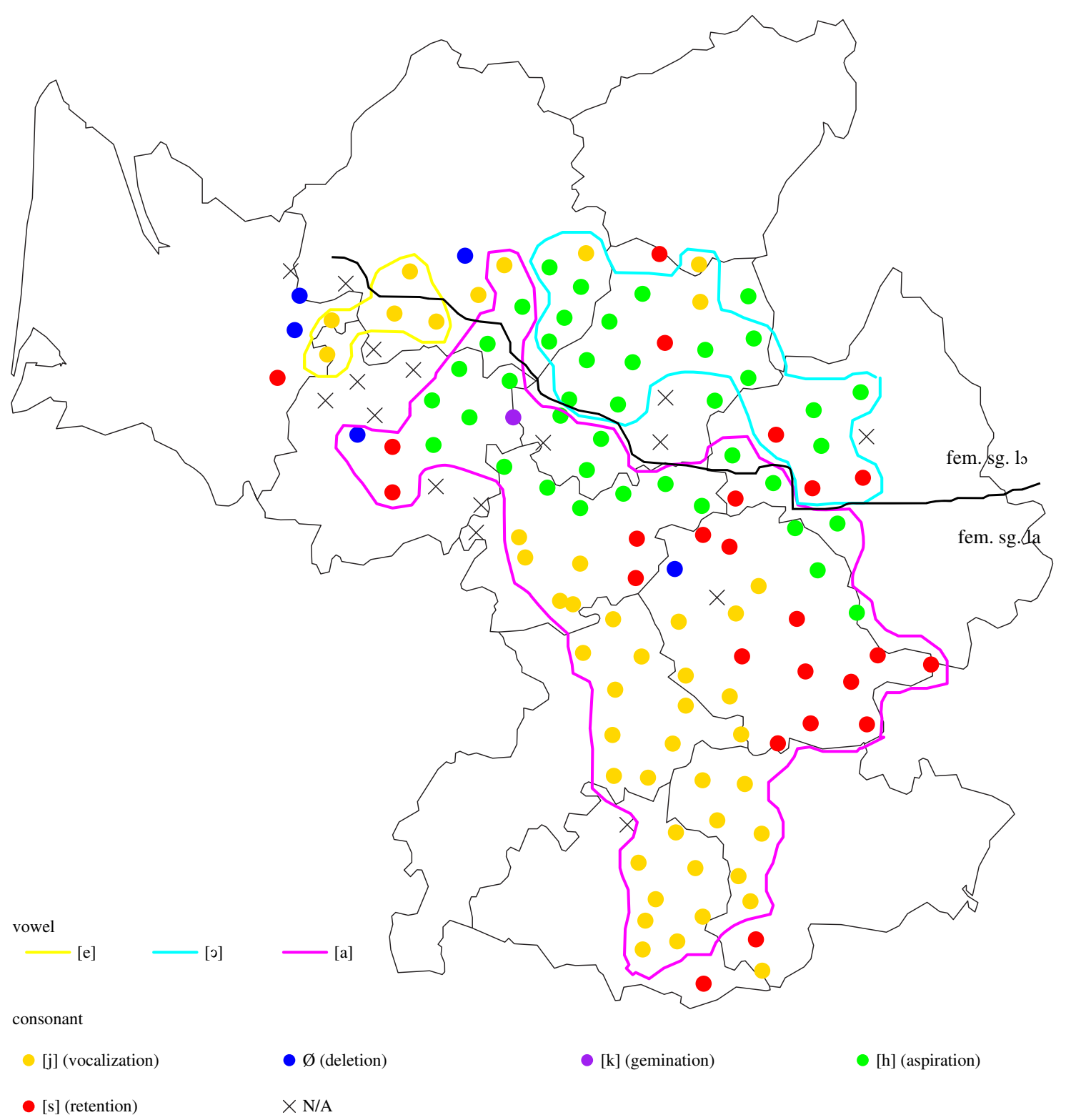

Map 11. Vowel quality of the plural definite article (isoglosses) and realization of /s/ on the article of les fleurs du vin (points). Black isogloss marks [lo]/[la] split in the singular definite article.

within a speaker or a community at the time the data were collected. Nevertheless, the atlas has a clear advantage over other linguistic methods in allowing rapid comparison between multiple regions. In the present study, such rapid comparison has revealed data that appears to support the importance of ambiguous or near-ambiguous forms for meaning preservation in the face of a process of lenition.

\section{Conclusions}

This paper has added data from the Languedocian dialect of Occitan to the vast typology of cases of /s/lenition in the world's languages. The dialect atlas data considered here have revealed that /s/-lenition in Languedocian includes a stage of vocalization to [j], which, when it occurs on a definite article, appears to trigger raising of a preceding vowel. This raising, a change which is mechanically actuated, apparently becomes used to preserve plurality in regions where /s/-weakening is advanced.

This study raises a number of further questions. Did /s/-loss in French go through a stage of vocalization as well, and is this the source of the mysterious /e/ in plural definite articles in that language? What has happened to the realization of plural on verbs in Languedocian, and can that be shown to have had any effect on plural marking in the noun phrase? After all, 
though the noun phrases in ALLOc were uttered in isolation, natural speech would of course provide additional sources of plural marking. Finally, preliminary analysis of masculine plural articles reveals that those in the advanced northwest sector take the shape [lu] in the singular but [lej] in the plural. Is this also (perhaps less articulatorily likely) a result of vowel mutation triggered by the following [j], or is this the result of analogy with the feminine article?

As is the case with many dialect atlases, ALLOc was conceived primarily to study lexical variation and was not strictly designed to examine sound changes: For instance, no attempt was made to target minimal pairs. Nevertheless, it has revealed a reasonable path by which the otherwise-unexplained /e/ in French plural articles may have come about, and has provided data relevant to theories of homophony avoidance and the maintenance of semantic distinctions.

\section{Notes}

1 The eight lexical items examined were les traces 'animal tracks' (ALLOc's map 352), les courroies du joug 'the bands of a yoke' (map 516), les ridelles 'walls of a cart' (map 552), les fleurs $d u$ vin 'yeasts that develop on the surface of wine' (map 754), les tranches de pain 'slices of bread used to garnish soup' (map 1058), le pantalon 'trousers' (map 1131), les jarretières 'garters' (map 1136), les incisives 'incisors' (map 1175).

${ }^{2}$ Ravier (1978:xiii, translation mine) transcribes this sound in $A L L O c$ notation as [i] and describes it as the "weak element" of a "decreasing diphthong" which does not form its own syllable. I follow other researchers (Floricic, 2010; Sauzet, 2012) as interpreting this as IPA [j].

3 Consonants noted by ALLOc as being "weakly articulated" are not differentiated in this or subsequent maps from consonants that were articulated normally.

${ }^{4}$ One might expect to see included in this list of realizations of /s/ its aspiration to [h], a common stage of /s/-lenition across languages (Ferguson, 1990; Seklaoui, 1989). Indeed, Map 4 will show that aspiration is a common realization of /s/ on the definite article. The lack of aspiration observed on the noun is most likely due to a prohibition on phrasefinal [h] (which would appear on the noun); the lexical items elicited for $A L L O c$ were produced in isolation, with nothing following the noun.

${ }^{5}$ Calculations of percentages were done after N/A tokens were omitted, so for localities where N/As were recorded for one or more lexical items, the denominator of the fraction was less than eight.

${ }^{6}$ Only one locality (24.10) ever shows deletion of /s/ on the article; it is accompanied by lengthening of the article vowel.

7 Sauzet (2012) similarly notes the correspondence between the region of vowel change in the definite article and the region of /s/ deletion on the noun, and briefly mentions a possible role of article-final [j].

\section{Acknowledgements}

Many thanks to William Labov, who provided invaluable comments at every stage of this work, audiences at the University of Pennsylvania and at NWAV38, and two anonymous reviewers for their comments.

\section{References}

Anglade, Joseph. [1921] 1977. Grammaire de l'ancien Provençal ou ancienne Langue d'Oc: Phonetique et morphologie. Paris: Editions Klincksieck.

Barra-Jover, Mario. 2012. L'évolution des marques de pluriel nominal roman à la lumière de l'occitan. In Mario Barra-Jover, Guylaine Brun-Trigaud, Jean-Philippe Dalbera, Patrick Sauzet \& Tobias Scheer (eds.), Etudes de linguistique gallo-romane, 201-216. Paris: Presses Universitaires de Vincennes.

Cedergren, Henrietta. 1973. The interplay of social and linguistic factors in Panama. Ithaca, NY: Cornell University dissertation.

Chambers, J.K. \& Peter Trudgill. 1998. Dialectology, 2nd edn. Cambridge: Cambridge University Press.

Eckert, Dorothy A. 1969. Grammatical constraints in phonological change: The unstressed vowels of Southern France. New York, NY: Columbia University thesis.

Eckert, Penelope. 1985. Grammatical constraints in phonological change: Unstressed *a in Southern France. Orbis 31. 169-189.

Ferguson, Charles. 1990. From esses to aitches: Identifying pathways of diachronic change. In Thom Huebner (ed.), Sociolinguistic perspectives: Papers on language in society, 1959-1994, 200-215. Oxford: Oxford University Press.

Floricic, Franck. 2010. Remarques sur le marquage du nombre dans le parler occitan de Veyrines-de-Vergt. In Franck Floricic (ed.), Essais de typologie et de linguistique générale: Mélanges offerts à Denis Creissels, 417-433. Lyon: ENS Editions.

Guy, Gregory R. 1981. Linguistic variation in Brazilian Portuguese: Aspects of the phonology, syntax, and language history. Philadelphia, PA: University of Pennsylvania dissertation.

Héran, François, Alexandra Filhon \& Christine Deprez. 2002. La dynamique des langues en France au fil du XXe siècle. Population et Sociétés 376. 1-4.

Hernández-Campoy, Juan Manuel \& Peter Trudgill. 2002. Functional compensation and southern peninsular Spanish /s/ loss. Folia Linguistica Historica 23. 31-57.

Labov, William. 1994. Principles of linguistic change, vol. 1: Internal factors. (Language in Society 20). Malden, MA: Blackwell.

Lewis, M. Paul, Gary F. Simons \& Charles D. Fennig. (eds.) 2014. Ethnologue: Languages of the world, 17th edn. Dallas, Texas: SIL International. Online version: http:/ /www. ethnologue.com

Moseley, Christopher (ed.). 2010. Atlas of the world's languages in danger, 3rd edn. Paris, UNESCO Publishing, Online version: http://www.unesco.org/culture/en/ endangeredlanguages/atlas 
Pope, M. K. 1952. From Latin to Modern French, with especial consideration of Anglo-Norman: Phonology and morphology. Manchester: Manchester University Press.

Poplack, Shana. 1980. Deletion and disambiguation in Puerto Rican Spanish. Language 56. 371-385.

Ranson, Diana. 1991. Person marking in the wake of /s/ deletion in Andalusian Spanish. Language Variation and Change 3. 133-152.

Ravier, Xavier. 1978. Atlas linguistique et ethnographique du Languedoc occidental, vol. 1. Paris: Editions du Centre National de la Recherche Scientifique.

Ravier, Xavier. 1982. Atlas linguistique et ethnographique du Languedoc occidental, vol. 2. Paris: Editions du Centre National de la Recherche Scientifique.

Ravier, Xavier. 1986. Atlas linguistique et ethnographique du Languedoc occidental, vol. 3. Paris: Editions du Centre National de la Recherche Scientifique.

Ravier, Xavier. 1993. Atlas linguistique et ethnographique du Languedoc occidental, vol. 4. Paris: Editions du Centre National de la Recherche Scientifique.
Ronjat, Jules. 1932. Grammaire istorique des parlers provençaux modernes, vol. 2. Montpellier: Société des Langues Romanes.

Sauzet, Patrick. 2012. Occitan plurals: A case for a morphemebased morphology. In Sascha Gaglia \& Marc-Olivier Hinzelin (eds.), Inflection and word formation in Romance languages, 179-200. Philadelphia: John Benjamins.

Schiffman, Harold. 1996. Linguistic culture and language policy. London: Routledge.

Seklaoui, Diane R. 1989. Change and compensation: Parallel weakening of [s] in Italian, French, and Spanish. New York: Peter Lang.

Spence, N. C. W. 1976. A note on the history of the French definite article le/la/les. Romance Philology 29. 311-318.

Terrell, Tracy. 1977. Constraints on the aspiration and deletion of final /s/ in Cuban and Puerto Rican Spanish. Bilingual Review/La Revista Bilingüe 4. 35-51.

Wheeler, Max W. 1988. Occitan. In Martin Harris \& Nigel Vincent (eds.), The Romance languages, 247-278. Oxford: Oxford University Press. 